\title{
Determination of Ceftriaxone Sodium in Pharmaceutical Formulations by Flow Injection Analysis with Acid Potassium Permanganate Chemiluminescence Detection
}

\author{
Deyi Zhang,* Yongjun Ma,* Min Zhou,* Li LI,* and Hui Chen*** \\ *Institute of Chemistry, Northwest Normal University, Lanzhou 730070, P. R. China \\ **Gansu Key Laboratory of Polymer Materials, Lanzhou 730070, P. R. China
}

\begin{abstract}
Based on the chemiluminescence (CL) emission generated from the oxidation of ceftriaxone sodium alkali hydrolysate by potassium permanganate in polyphosphoric acid (PPA), a novel determination method for ceftriaxone sodium was developed by using a flow-injection technique. The calibration curve appears to be linear in the range between 0.05 and $100 \mu \mathrm{g} \mathrm{mL} \mathrm{g}^{-1}$ with a detection limit $(3 \sigma)$ of $25 \mathrm{ng} \mathrm{mL}^{-1}$, and a relative standard deviation (RSD) of $0.6 \%$ for eleven replicate determinations of $5.0 \mu \mathrm{g} \mathrm{mL}^{-1}$ ceftriaxone sodium. The proposed method has been successfully utilized for the determination of ceftriaxone sodium in pharmaceutical formulations, while the chemiluminescence reaction mechanisms were investigated.
\end{abstract}

(Received September 18, 2005; Accepted November 18, 2005)

\section{Introduction}

Ceftriaxone sodium, as a semisynthetic third-generation cephalosporin, has a broad spectra against gram-positive and gram-negative bacteria. It is effective in the treatment of various infections caused by accurate bacteria, blood poisoning, meningitis and gonorrhea in clinic. According to published literature, the various chromatographic methods, including conventional LC, HPLC and HPTLC, have been proposed for the detection of ceftriaxone sodium in pharmaceuticals or in body fluids, respectively. ${ }^{1-4}$ Other analytical procedures, such as fluorometric and spectrophotometric determinations, were reported. ${ }^{5-7}$

Due to its inherent high sensitivity and low detection limit, CL has been extensively applied in pharmaceuticals analysis. ${ }^{8,9}$ The acid potassium permanganate CL reaction, as a commonly used chemiluminescence determination system in pharmaceuticals analysis, ${ }^{10}$ has been utilized in the determination of some cephalosporins. Aly et al. successfully detected $5 \mathrm{ng} \mathrm{ml}^{-1}$ cefadroxil monohydrate based on a $\mathrm{CL}$ reaction of cefadroxil with potassium permanganate in sulfuric acid sensitized by quinine. ${ }^{11}$ Sun et al. also reported a flow injection analysis method for the determination of $10 \mathrm{ng} \mathrm{ml}^{-1}$ cefalexin, $2 \mathrm{ng} \mathrm{ml}^{-1}$ cefadroxil, and $2 \mathrm{ng} \mathrm{ml}^{-1}$ cefazolin sodium, respectively, utilizing the enhancing effect of above-mentioned cephalosporins on the chemiluminescence reaction of glyoxal with potassium permanganate under acid condition. ${ }^{12}$ However, the above-described analytical procedures have no available responses for ceftriaxone sodium. Generally, only weak chemiluminescence emission could be observed when acid potassium permanganate directly reacted with the analytes. To be used in analytical applications, this CL reaction must be

To whom correspondence should be addressed.

E-mail: lzchenh@sina.com.cn sensitized by selected enhancers, such as quinine or formaldehyde. ${ }^{11,13}$ However, this procedure could make the determination more complicated and the confirmation of CL emitter more difficult. In the present work, it was found that the oxidation of the ceftriaxone sodium hydrolysate by potassium permanganate in polyphosphoric acid could generate intense chemiluminescence, and the intensity of the chemiluminescence was proportional to the concentration of ceftriaxone sodium. Based on this experimental fact, a novel determination method for ceftriaxone sodium in pharmaceutical formulations was investigated by using a flow-injection technique. In comparison with the conventional HPLC, the proposed method has a series of advantages, such as simple, accurate, quick, broad detection range and high sensitivity.

\section{Experimental}

\section{Chemicals}

A standard solution of $200 \mu \mathrm{g} \mathrm{mL}-1$ ceftriaxone sodium (Uniche, America) was prepared by dissolving $20 \mathrm{mg}$ of ceftriaxone sodium directly in $100 \mathrm{~mL}$ of water.

In the preparation of ceftriaxone sodium hydrolysate: some volume of a ceftriaxone sodium standard solution and $1.0 \mathrm{~mL}$ of a $1.5 \times 10^{-2} \mathrm{M} \mathrm{NaOH}$ solution were mixed in a $25 \mathrm{~mL}$ colorimetry tube and diluted to $10 \mathrm{~mL}$. The mixing solutions was then incubated in a boiling water bath for $15 \mathrm{~min}$, followed by cooling in ice-water immediately.

A $\mathrm{KMnO}_{4}$ stock solution of $2.0 \times 10^{-2} \mathrm{M}$ and $0.1 \mathrm{M}$ polyphosphoric acid were prepared by the usual ways. All chemicals used were of analytical reagent grade, unless otherwise stated, and were diluted with distilled water.

\section{Apparatus}

An IFFL-D flow-injection CL system (Xi' an Record Electric Ltd. Corp., China) was used for solution transmission, mixing 


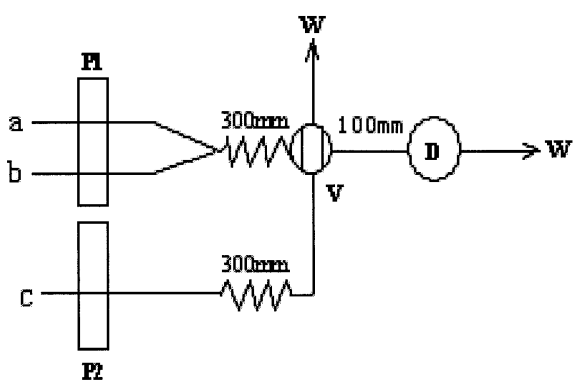

Fig. 1 Schematic diagram of the CL-FIA manifold used for the determination of ceftriaxone sodium. P1 and P2, peristaltic pump; V, injection valve; $\mathrm{D}$, detector; $\mathrm{W}$, waste solution; a, $1.0 \times 10^{-2} \mathrm{M}$ PPA; b, ceftriaxone sodium hydrolysate; c, $3.0 \times 10^{-4} \mathrm{M} \mathrm{KMnO}_{4}$.

and chemiluminescence signal detection. All of the experimental parameters were controlled by computer programs. A LS55 luminescence spectrophotometer (Perkin Elmer, USA) was used for chemiluminescence spectra measurements.

\section{Procedure}

The flow system, as illustrated in Fig. 1, was based on a zone technique. A peristaltic pump (P1) was used to deliver and mix the carrier solution $\left(1.0 \times 10^{-2} \mathrm{M}\right.$ PPA $)$ and ceftriaxone sodium hydrolysate. Another peristaltic pump (P2) was used to deliver the oxidant $\left(3.0 \times 10^{-4} \mathrm{M} \mathrm{KMnO}_{4}\right)$ into a sample loop $(150 \mu \mathrm{l}$, $100 \mathrm{~mm}$ length), which then joined the former stream and was finally injected into the detector (D) through a PTFE mixing tube (100 mm length, $0.8 \mathrm{~mm}$ i.d). The $\mathrm{CL}$ signal (no wavelength selection) was recorded after being enhanced by a photomultiplier tube at $750 \mathrm{~V}$ (negative voltage).

The chemiluminescence spectrum was inspected by the bioluminescence program LS55 luminescence spectrophotometer. When the bioluminescence program was chosen, the excitation source was closed automatically, and then using the scan function of the spectrophotometer, the signal profile of CL emission was recorded by the computer program. In the experiment, $2.5 \mathrm{~mL}$ of the mixing solution of ceftriaxone sodium hydrolysate and a PPA was added into a quartz cell, and then a $1.0 \mathrm{~mL} \mathrm{KMnO}_{4}$ solution was quickly injected into the same cell when the scan function was executed. In order to obtain high sensitivity, the gate time and the circle time were set at $180 \mathrm{~nm}$ and $200 \mathrm{~nm}$, respectively, the scan speed at 700 $\mathrm{nm} / \mathrm{min}$, and the emission slit at $15 \mathrm{~nm}$.

\section{Results and Discussion}

\section{Effect of the hydrolyze condition}

In the present work, it was found that all of the ceftriaxone sodium, ceftriaxone sodium alkali hydrolysate and acidified hydrolysate, oxidized by potassium permanganate in PPA medium could generate chemiluminescence. Nevertheless, the CL produced by ceftriaxone sodium alkali hydrolysate was stronger and more stable than by others. Thus, a $\mathrm{NaOH}$ solution was selected as the medium of hydrolyze reaction. The effects of $\mathrm{NaOH}$ concentration and the hydrolyze time on the CL response were also investigated, respectively. The results showed that alkali hydrolysate, which was prepared by hydrolyzing ceftriaxone sodium in a $1.5 \times 10^{-3} \mathrm{M} \mathrm{NaOH}$ solution for $15 \mathrm{~min}$ and incubating in a boiling water bath, appeared to be superior in emission intensity.

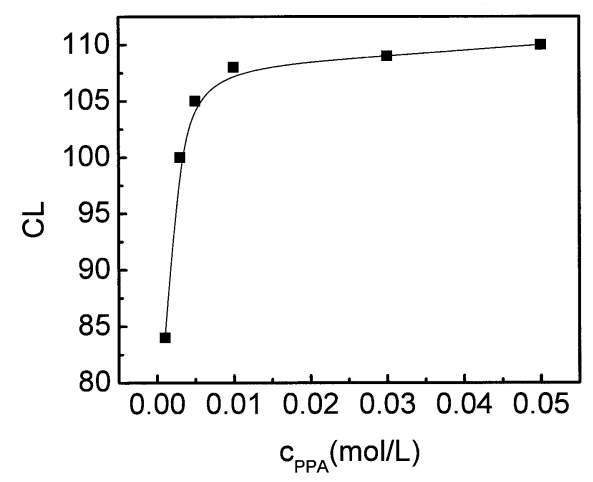

Fig. 2 Effect of PPA concentration on the CL intensity. Ceftriaxone sodium hydrolysate, $5 \mathrm{mg} \mathrm{L}^{-1} ; \mathrm{KMnO}_{4}, 3.0 \times 10^{-4} \mathrm{M}$.

\section{Effect of the CL reaction medium}

In order to evaluate the effect of the reaction medium on chemiluminescence emission, various inorganic acids, such as $\mathrm{H}_{2} \mathrm{SO}_{4}, \mathrm{HCl}, \mathrm{HNO}_{3}, \mathrm{H}_{3} \mathrm{PO}_{4}$ and PPA, were investigated. The results showed that the presence of PPA resulted in the greatest sensitivity in the oxidation of ceftriaxone sodium hydrolysate by potassium permanganate, which may have been due to the PPA as an emission promoter for acidic potassium permanganate CL system. The effect of varying PPA concentrations on the chemiluminescence response is shown in Fig. 2. A steep rise in the chemiluminescence intensity was observed in the presence of PPA from $1.0 \times 10^{-3} \mathrm{M}$ to $1.0 \times 10^{-2} \mathrm{M}$ again demonstrated the ability of this reagent to significantly enhance the generation of this type of chemiluminescence..$^{14,15}$ Thus, the experiment chose $1.0 \times 10^{-2} \mathrm{M}$ PPA as the optimum reaction medium.

\section{Effect of the potassium permanganate concentration}

The effect of varying the potassium permanganate concentration between $5.0 \times 10^{-5} \mathrm{M}$ and $5.0 \times 10^{-4} \mathrm{M}$ on the CL emission was examined. The chemiluminescence intensity increased steeply, and reached the maximum by increasing the potassium permanganate concentration up to $3.0 \times 10^{-4} \mathrm{M}$. Then, a larger concentration of potassium permanganate would not induce an apparent increase in the chemiluminescence response. Thus, $3.0 \times 10^{-4} \mathrm{M}$ potassium permanganate was used in this experiment. It was also noted that when $\mathrm{KMnO}_{4}$ and PPA as carrier solutions were carried continuously with a pump, but the sample solution was injected into the sample loop, no available CL emission was observed. Only when $\mathrm{KMnO}_{4}$ was injected into the sample loop directly and the mix solution of the sample and PPA was carried continuously with a pump as the carrier solution, could the intense chemiluminescence be generated. Thus, $\mathrm{KMnO}_{4}$ should be injected into the sample loop in the experiment.

\section{Interferences}

In order to assess the potential interference, the effect of various common inorganic ions and medicament excipient on the response of $5 \mu \mathrm{g} \mathrm{mL}^{-1}$ ceftriaxone sodium hydrolysate was investigated. It was considered that no apparent interference occurred if the relative error caused by foreign material was less than $\pm 5 \%$. The results showed that no apparent interference was found when including up to a 500 -fold $\mathrm{K}^{+}, \mathrm{Na}^{+}, \mathrm{NH}_{4}{ }^{+}, \mathrm{Cl}^{-}$, $\mathrm{SO}_{4}{ }^{2-}, \mathrm{NO}_{3}{ }^{2-} ; 200$-fold $\mathrm{Zn}^{2+}, \mathrm{Mg}^{2+}$, dextrin, fructose; 50-fold saccharose, sorbierite, lactose; 10-fold $\mathrm{Ca}^{2+}, \mathrm{Ni}^{2+}, \mathrm{Fe}^{2+}$, galactose, glucose. 
Table 1 Analytical characteristics of the proposed method and HPLC method

\begin{tabular}{lcccc}
\hline Method & $\begin{array}{c}\text { Condition } \\
\text { range/ } \\
\mu \mathrm{g} \mathrm{mL}^{-1}\end{array}$ & $\begin{array}{c}\text { Calibration } \\
\text { equation } \\
I=a+b C\end{array}$ & $\begin{array}{c}\text { Correlation } \\
\text { coefficient } \\
(n=11)\end{array}$ & $\begin{array}{c}\text { Detection } \\
\text { limit/ } \\
\mathrm{ng} \mathrm{mL}^{-1}\end{array}$ \\
\hline $\begin{array}{l}\text { Proposed } \\
\text { method }\end{array}$ & $0.05-20$ & $19.20 C+7.91$ & 0.9996 & \\
$\begin{array}{l}\text { Proposed } \\
\text { method }\end{array}$ & $20-100$ & $13.18 C+127.82$ & 0.9995 & 25 \\
$\begin{array}{l}\text { HPLC } \\
\text { method }\end{array}$ & $5-20$ & $5.87 C+0.92$ & 0.9947 & 250 \\
\hline
\end{tabular}

Table 2 Results for the determination of ceftriaxone sodium in dosage form

\begin{tabular}{lccccc}
\hline \multicolumn{1}{c}{ Sample } & $\begin{array}{c}\text { Sample } \\
\text { content/ } \\
\mu \mathrm{g} \mathrm{mL}^{-1}\end{array}$ & $\begin{array}{c}\text { Present } \\
\text { method/ } /\end{array}$ & $\begin{array}{c}\text { Added/ } \\
\mu \mathrm{g} \mathrm{mL}^{-1}\end{array}$ & $\begin{array}{c}\text { Found/ } \\
\mu \mathrm{g} \mathrm{mL}^{-1}\end{array}$ & $\begin{array}{c}\text { Recovery, } \\
\% \\
(n=5)\end{array}$ \\
\hline No B04034613 & 5.00 & 4.86 & 5.00 & 5.09 & 101.8 \\
No B040603112 & 5.00 & 4.87 & 5.00 & 5.07 & 101.4 \\
No 0401533 & 5.00 & 4.66 & 5.00 & 5.12 & 102.4 \\
No 040153 & 5.00 & 4.68 & 5.00 & 5.10 & 102.0 \\
\hline
\end{tabular}

\section{Analytical characteristics and application}

Under the optimum experimental conditions described previously, the calibration graphs of the CL intensity versus the ceftriaxone sodium concentration and detection limits $(S / N=3)$ were obtained (listed in Table 1). The reproducibility of the proposed method was better, as demonstrated by a relative standard deviations of $0.6 \%$ for $5.0 \mu \mathrm{g} \mathrm{mL}^{-1}$ ceftriaxone sodium $(n=11)$. The analytical characteristics of the conventional HPLC method ${ }^{3}$ are also given in Table 1. Compared with the HPLC method, the proposed method has a series of advantages, such as simple, accurate, quick, broad detection range and high sensitivity.

The proposed method was applied to the determination of ceftriaxone sodium in dosage form produced by different companies. The results are listed in Table 2.

\section{Possible chemiluminescence mechanism}

Although the acidified potassium permanganate chemiluminescence system has been widely studied, the origin of the luminescence and the mechanisms that lead to the production of an excited state have thus far not been elucidated. The excited state $\mathrm{Mn}(\mathrm{II})^{16}$ and singlet oxygen $\left({ }^{1} \Delta g\right)^{17}$ were postulated as two types, mostly possible emitting species, but neither excited state $\mathrm{Mn}(\mathrm{II})$ or singlet oxygen $\left({ }^{1} \Delta g\right)$ could be supported by certain CL spectra, because of lacking a special inspecting instrument for the CL spectra. The complete CL spectra of $\mathrm{KMnO}_{4}$-ceftriaxone sodium hydrolysate-PPA system was inspected by the special bioluminescence program of LS55 luminescence spectrophotometer in order to obtain more information about the emitter of the acid potassium permanganate CL system. As shown in Fig. 3, the CL spectra were composed of three apparent emitting bands located at 595, 626 , and $658 \mathrm{~nm}$, respectively. Otherwise, an apparent shoulder peak was found at $611 \mathrm{~nm}$. The emitting band located at $c a$. $595 \mathrm{~nm}$ could be affirmed as the characteristic CL band of the excited state $\mathrm{Mn}(\mathrm{II})$ due to the fact that the photoluminescence of solid state $\mathrm{Mn}(\mathrm{II})$ in phosphate glass, observed by Kumar, ${ }^{18}$ located at $c a .595 \mathrm{~nm}$. The emitting bands located at 626 and

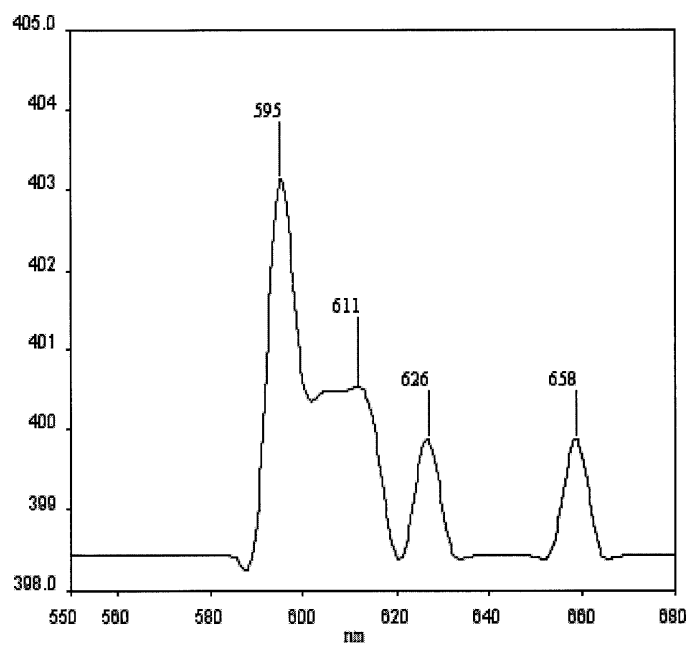

Fig. 3 CL spectra of the reaction system. Ceftriaxone sodium hydrolysate, $50 \mathrm{mg} \mathrm{L}^{-1} ; \mathrm{KMnO}_{4}, 1.0 \times 10^{-3} \mathrm{M} ; \mathrm{PPA}, 1.0 \times 10^{-3} \mathrm{M}$.

$658 \mathrm{~nm}$ were postulated as originating from singlet oxygen $\left({ }^{1} \Delta g\right)$, but Barnett et al. negated this possibility in their research. ${ }^{16}$ Because there have many evidence proving that the emitting species of this type chemiluminescence reaction was not an oxidation product of the substrate, but rather a reduction intermediates of manganese, ${ }^{16}$ it would seem to be reasonable to propose that the exited triplet state $\mathrm{Mn}$ (II) was the CL emitting species in the present determination reaction, and was responsible for all of the emitting bands shown in Fig. 3. Because the oxidation of the ceftriaxone sodium hydrolysate by potassium permanganate in PPA is a quantifying reaction, the chemiluminescence intensity and ceftriaxone sodium concentration have a good proportional relation over a broad range. The presence of PPA could enlarge this relation due to the significantly enhanced effect of PPA on this chemiluminescence reaction. Based on this reaction mechanism, the available procedure for the determination of ceftriaxone sodium was proposed.

\section{Conclusion}

A novel analytical procedure for determining ceftriaxone sodium has been described. Compared with the HPLC method, the proposed method has a series of advantages, such as simple, accurate, quick, broad detection range and high sensitivity. It can also meet the need for quick determination of the ceftriaxone sodium concentration in pharmaceuticals. The chemiluminescence spectrum of reaction system was inspected by a special instrument, and then the chemiluminescence mechanism of the reaction system was considered. The results indicated that the excited triplet state $\mathrm{Mn}$ (II) was the main chemiluminescence emitting species.

\section{Acknowledgements}

This work was supported by the Gansu Province Nature Science Foundation of China (No. 3ZS041-A25-027 and No. 3ZS051A25-097). All of the authors wish to make a grateful acknowledgement. 


\section{References}

1. H. M. Owens, C. J. Destache, and A. K. Dash, J. Chromatogr. B, 1999, 728, 97.

2. S. Al-Rawithi, R. Hussein, D. A. Raines, I. Al-Showaier, and Wesam Kurdi, J. Pharm. Biomed. Anal., 2000, 22, 281.

3. Abdel-Hamid and E. Mohammed, IL Farmacol, 1998, 53, 132.

4. S. Eric-Jovanovic, D. Agbaba, D. Zivanov-Stakic, and S. Vladimirov, J. Pharm. Biomed. Anal., 1998, 18, 893.

5. L. I. Bebawy, K. E. Kelani, and L. A. Fattah, J. Pharm. Biomed. Anal., 2003, 32, 1219.

6. I. F. Al-Momani, J. Pharm. Biomed. Anal., 2001, 25, 751.

7. A. S. Amin and G. H. Ragab, Spectrochim. Acta A, 2004, 60, 2831.

8. S. M. Sultan, Y. A. M. Hassan, and A. M. Abulkibash, Talanta, 2003, 59, 1073.

9. L. Weibing and H. Yuming, Anal. Chim. Acta, 2004, 506,
183.

10. B. J. Hindson and N. W. Barnett, Anal. Chim. Acta, 2001, $445,1$.

11. F. A. Aly, N. A. Alarfaffj, and A. A. Alwarthan, Talanta, 1998, 47, 471.

12. Y. Sun, Y. Tang, H. Yao, and X. Zheng, Talanta, 2004, 64, 156.

13. F. Nie, Y. Wu, and J. Lü, Chin. J. Anal. Chem., 2003, 31, 512.

14. N. T. Deftereos, N. Grekas, and A. C. Calokerinos, Anal. Chim. Acta, 2000, 403, 137.

15. A. Mitsana-Papazoglou, A. Fragaki, P. Chamosfakidi, and A. C. Calokerinos, Anal. Chim. Acta, 2000, 410, 153.

16. N. W. Barnett, B. J. Hindson, P. Jones, and T. A. Smithm, Anal. Chim. Acta, 2002, 451, 181.

17. S. Yuanyuan, T. Yuhai, Y. Hong, and Z. Xiaohui, Talanta, 2004, 64, 156.

18. G. A. Kumar, P. R. Biju, J. Gin, and N. V. Unnikrishnan, Mater. Chem. Phys., 1999, 60, 247. 